\title{
Segurança alimentar de hortaliças orgânicas: aspectos sanitários e nutricionais
}

\author{
Organic vegetables safety: sanitary and nutritional aspects
}

\author{
Kettelin Aparecida ARBOS ${ }^{1 \star}$, Renato João Sossela de FREITAS ${ }^{1}$, \\ Sônia Cachoeira STERTZ ${ }^{1}$, Lucimar Aparecida CARVALHO ${ }^{2}$
}

\begin{abstract}
Resumo
A procura por alimentos orgânicos é expressiva em todo o mundo devido à conscientização da população sobre os riscos para a saúde decorrentes da presença de resíduos químicos nos alimentos. Vários trabalhos sugerem que algumas práticas do sistema orgânico, como o uso de esterco animal e a proibição de aplicação de agrotóxicos possam aumentar o risco de uma contaminação microbiológica e parasitária, tornando o alimento não adequado ao consumo. Dessa forma, a presente pesquisa teve como objetivo determinar a qualidade sanitária de hortaliças orgânicas no que se refere à contaminação microbiológica por coliformes totais e fecais, presença de Salmonella sp. e contaminação parasitológica. Adicionalmente, descreveu-se a qualidade nutricional através de análises de características físico-químicas de alface, tomate e cenoura cultivados organicamente, provenientes da Região Metropolitana de Curitiba-PR. Coliformes fecais foram detectados em $40 \%$ das amostras de alface e em $25 \%$ das amostras de cenoura. A presença de Salmonella sp. foi verificada em $25 \%$ das amostras de cenoura e em $20 \%$ das amostras de alface. As amostras de tomate orgânico avaliadas apresentaram ausência de coliformes fecais e Salmonella sp. Os principais parasitas identificados nas amostras de alface orgânica foram: Entamoeba sp., ovos de ácaro, ovos de ancilostomídeo e insetos (pulgões). Nas amostras de cenoura orgânica foram identificados ovos de ancilostomídeo, cistos de Entamoeba sp. e ovos de Toxocara sp. Nenhuma estrutura parasitária foi identificada nas amostras de tomate orgânico. A presença de coliformes fecais, Salmonella sp. e estruturas parasitárias em algumas amostras de alface e cenoura orgânicas demonstraram que foram contaminadas de alguma forma, seja através da água de irrigação, presença de animais silvestres ou domésticos, solo contaminado ou emprego de adubos sem tempo de compostagem adequado.
\end{abstract}

Palavras-chave: hortaliças; cultivo orgânico; qualidade sanitária; valor nutricional.

\begin{abstract}
The search for organic foods is expressive worldwide due to the population awareness about the health risks resulting from the presence of chemical residues in food. Several studies suggest that some practices of organic farming, such as the use of animal manure and rules prohibiting the use of conventional pesticides, can increase the microbiological and parasitic risks. Hence, these foods would not be suitable for human consumption. In this context, the present research aimed at determining the sanitary quality of organic vegetables through the evaluation of microbiological contamination by total and fecal and coliforms, Salmonella sp., and parasitological contamination. Moreover, samples of organic lettuce, carrots, and tomatoes from the Metropolitan Region of Curitiba, Paraná, were submitted to physicochemical evaluation to assess their nutritional quality. Thermotolerant coliforms, or fecal coliforms, were detected in $40 \%$ of the lettuce and in $25 \%$ of the carrot samples. It was observed that $25 \%$ of the carrot and $20 \%$ of lettuce samples presented Salmonella sp., whereas the tomato samples did not present thermotolerant coliforms or Salmonella sp. The major parasites identified in the lettuce samples were acarus, Entamoeba sp., eggs of Ancylostoma sp., and insects. Entamoeba sp., eggs of Ancylostoma sp. and Toxocara sp. were identified in the organic carrot samples, while the tomato samples did not present any parasitological contamination. The data suggest that the organic lettuce and carrot samples might have been contaminated somehow by the soil, water, domestic animals, or non-suitable fertilizers.

Keywords: vegetables; organic farming; sanitary quality; nutritional value.
\end{abstract}

\section{Introdução}

Nos últimos anos, a preocupação do homem com a qualidade e a segurança dos alimentos vem crescendo. Por essa razão, na escolha dos alimentos, os consumidores cada vez mais levam em consideração os riscos alimentares que os produtos podem oferecer, como as práticas higiênicas, os riscos microbiológicos, os métodos de produção, as aplicações de pesticidas, o uso da biotecnologia e várias outras inovações tecnológicas (FREWER;
SHEPHERD; SPARKS, 1994; SABA; ROSATI; VASSALLO, 2000; CHINNICI; DÁMICO; PECORINO, 2002).

Todos os alimentos devem ser produzidos seguindo práticas que resultem em produtos seguros para serem consumidos. Essa premissa é verdadeira tanto para o sistema orgânico de cultivo, como para o convencional. No entanto, algumas questões têm sido levantadas a respeito da possibilidade de um

\footnotetext{
Recebido para publicação em 22/7/2008

Aceito para publicação em 7/7/2009 (003626)

1 Programa de Pós-Graduação em Tecnologia de Alimentos, Setor de Tecnologia, Universidade Federal do Paraná - UFPR, Centro Politécnico, CEP 81531-990, Curitiba-PR, Brasil, E-mail:kettelin.arbos@gmail.com

${ }^{2}$ Centro de Ciência e Tecnologia de Alimentos, Universidade Anhanguera - UNIDERP, Rua Alexandre Herculano, 1400, Jardim Veraneio, CEP 79480-000, Campo Grande-MS, Brasil,

E-mail: ccta@uniderp.br

${ }^{*}$ A quem a correspondência deve ser enviada.
} 
risco aumentado de contaminação microbiológica e parasitária nos alimentos produzidos no sistema orgânico, em virtude principalmente do tipo de adubação.

Stephenson (1997) sugere que algumas práticas do sistema orgânico, como o uso de esterco animal e a proibição de aplicação de agrotóxicos, possam aumentar o risco de uma contaminação e, desse modo, tornar o alimento não adequado ao consumo. Contudo, Smith (1993) menciona que contaminação microbiológica dependerá principalmente das práticas de produção adotadas na propriedade e das condições ambientais e, assim sendo, tanto os alimentos orgânicos como os convencionais estariam sujeitos ao mesmo nível de risco. Além disso, um alimento para ser comercializado como orgânico passa frequentemente por uma série de procedimentos exigidos pela certificadora, a qual não permite que o esterco animal seja utilizado antes da sua correta compostagem.

Em virtude da valorização da qualidade da dieta alimentar por parte dos consumidores, na qual a produção orgânica de alimentos tem merecido destaque, associada à escassez de dados relativos às questões envolvendo a qualidade sanitária de hortaliças orgânicas, este trabalho propôs não apenas a avaliação da qualidade microbiológica e parasitária de hortaliças provenientes de cultivo orgânico da Região Metropolitana de Curitiba - PR (RMC) como também determinar a qualidade nutricional e contribuir para a melhoria da segurança sanitária desses alimentos consumidos frequentemente pela população.

\section{Material e métodos}

\subsection{Amostras}

Foram visitados treze produtores orgânicos certificados situados na RMC nos municípios de São José dos Pinhais e Colombo, nos quais foram colhidos aleatoriamente amostras de cerca de $250 \mathrm{~g}$ de alface (Lactuca sativa L.), tomate (Lycopersicon esculentum Mill.) e cenoura (Daucus carota L.), no período compreendido entre maio e outubro de 2006.

As hortaliças foram coletadas com luvas cirúrgicas e acondicionadas em sacos plásticos de primeiro uso, identificados e preservados em caixas isotérmicas, contendo bolsas com gelo, com temperatura inferior a $10^{\circ} \mathrm{C}$. As amostras coletadas e devidamente acondicionadas foram encaminhadas ao laboratório para o início das análises.

\subsection{Análises microbiológicas}

As análises microbiológicas das hortaliças orgânicas foram realizadas segundo metodologias recomendadas pela ABNT (1991) e Apha (1992), sendo verificada a presença de Salmonella sp. e determinados os coliformes totais e coliformes fecais.

$\mathrm{Na}$ análise de coliformes, foi empregada a técnica dos tubos múltiplos, utilizando caldo lauril sulfato triptose (LST) com tubo de Durhan invertido como teste presuntivo. Dos tubos positivos no teste presuntivo, indicado pela presença de gás no tubo de fermentação (Durhan), realizou-se a confirmação de coliformes totais através de repicagem para tubos contendo caldo verde brilhante lactose bile $2 \%$, seguida de incubação em estufa por $24-48$ horas a $35^{\circ} \mathrm{C}$. Concomitantemente, realizou-se a confirmação de coliformes fecais através da repicagem em caldo Escherichia coli (EC) com incubação em banho-maria por 24-48 horas a $45^{\circ} \mathrm{C}$. Após o período de incubação, realizou-se a leitura dos tubos positivos e o número mais provável (NMP) foi quantificado através da leitura na Tabela de Hoskins (APHA, 1992).

\subsection{Análises parasitológicas}

Para a execução das análises parasitológicas, empregou-se a técnica de sedimentação descrita por Oliveira e Germano (1992) com modificações, proposta por Takayanagui et al. (2001). Assim, pesaram-se cerca de $100 \mathrm{~g}$ de cada vegetal em sacos de polietileno, introduziram-se $250 \mathrm{~mL}$ de água destilada e foram agitados manualmente por 30 segundos. O líquido obtido da lavagem foi filtrado através de gaze cirúrgica, recolhido em frascos com capacidade para $250 \mathrm{~mL}$, onde permaneceu em repouso por 24 horas para sedimentação. Após a sedimentação espontânea, o líquido sobrenadante foi cuidadosamente desprezado e o sedimento analisado em triplicata através de lâmina corada com solução de lugol e em exame direto com microscópio ótico, utilizando objetivas de 10 e 40 X para pesquisa de ovos ou larvas de helmintos. Parte do sedimento foi submetida ao método de centrífuga-flutuação em sulfato de zinco para pesquisa de cistos de protozoários.

\subsection{Análises físico-químicas}

A umidade foi determinada em estufa com circulação forçada de ar segundo as normas analíticas do IAL (2005). Os sólidos totais, cinzas, proteína, extrato etéreo (lipídios), fibra alimentar e $\mathrm{pH}$ foram determinados em base úmida, segundo os métodos descritos pela AOAC (2002). No cálculo do teor de proteína, utilizou-se fator de conversão de 6,25. A vitamina $C$ foi determinada por titulação com iodato de potássio (IAL, 2005). Os carboidratos totais foram calculados por diferença e o valor calórico foi calculado a partir da energia procedente dos nutrientes, considerando-se os fatores de conversão de Atwater (USP, 2007). A comparação do valor nutricional entre as hortaliças orgânicas e convencionais do presente estudo foi feita com os valores disponibilizados na TACO - Tabela Brasileira de Composição de Alimentos (UNICAMP, 2006).

\subsection{Análise estatística}

Os dados obtidos dos parâmetros físico-químicos analisados no presente trabalho foram avaliados estatisticamente pelo programa InSat versão 3.06. A significância estatística foi estudada através da análise de variância (ANOVA) e teste de Tukey $(\mathrm{p}<0,05)$.

\section{Resultados e discussão}

\subsection{Avaliação microbiológica}

A contaminação de hortaliças por agentes patogênicos verifica-se, principalmente, por meio de água contendo material fecal de origem humana, utilizada na irrigação de hortas ou 
ainda contaminação do solo por uso de adubo orgânico com dejetos fecais.

A legislação brasileira (BRASIL, 2001) através da RDC $\mathrm{n}^{\circ} 12$, de 2 de janeiro de 2001, estabelece limites microbiológicos para coliformes fecais e Salmonella sp. em hortaliças in natura. Segundo essa regulamentação, as hortaliças in natura podem apresentar até $10^{2} \mathrm{NMP.g}^{-1}$ de coliformes fecais e ausência de Salmonella sp. Embora o presente trabalho tenha avaliado as condições microbiológicas de hortaliças orgânicas, utilizaram-se os mesmos critérios empregados para hortaliças convencionais devido à inexistência de parâmetros para alimentos provenientes de cultivo orgânico.

A Tabela 1 apresenta os valores encontrados para coliformes totais, coliformes fecais e Salmonella sp. nas amostras analisadas. Embora não existam limites para coliformes totais na legislação brasileira, tais análises foram realizadas considerando-se que os resultados positivos indicam condições inadequadas de higiene do local, do produto e risco da presença de patógenos nesses alimentos.

Duas amostras de alface (produtores 1 e 2) e uma amostra de cenoura (produtor 13) apresentaram contagens de coliformes de origem fecal acima do permitido pela legislação brasileira. Balioni et al. (2003) analisaram amostras de alface cultivadas sob manejo agroecológico e convencional da cidade de Campinas - SP e verificaram que $75 \%$ das amostras de alface agroecológicas e $85 \%$ das alfaces convencionais estavam contaminadas por coliformes fecais.

Conforme citado por Obuobie et al. (2006), a Comissão Internacional de Especificações Microbiológicas para Alimentos estabelece limite de coliformes fecais em hortaliças frescas de $1,0 \times 10^{3} \mathrm{NMP}^{-1}{ }^{-1}$. Em relação a esse critério, apenas a amostra de alface do produtor 1 estaria em desacordo, uma vez que apresentou 2,4 × $10^{3} \mathrm{NMP.g}^{-1}$ de coliformes fecais.

É importante salientar que as amostras de tomate orgânico analisadas neste trabalho mostraram um excelente padrão microbiológico, visto que apresentaram contagem baixa de coliformes totais e ausência de coliformes fecais e Salmonella sp. Oliveira et al. (2006), ao analisarem amostras de tomate comercializadas em feiras livres de Belém - PA, também encontraram menor contaminação dessa hortaliça em relação às demais espécies analisadas.

Com referência à presença de Salmonella sp., verificou-se que apenas as amostras de alface do produtor 2 e de cenoura do produtor 13 encontravam-se em desacordo com a legislação brasileira, que estabelece ausência desse microrganismo em hortaliças (BRASIL, 2001).

Nas amostras de alface de diferentes cultivos analisadas por Santana et al. (2006), não foi detectada a presença de Salmonella sp. Os autores verificaram também que as amostras de alface provenientes de cultivo orgânico apresentaram maior contagem de coliforme de origem fecal que as amostras de alface convencional e hidropônica.

\subsection{Avaliação parasitológica}

A Tabela 2 mostra a frequência das estruturas parasitárias nas amostras de alface, tomate e cenoura provenientes de cultivo orgânico dos diferentes produtores avaliados. Esses produtores foram divididos pelo tipo de hortaliça cultivada, desconsiderando a frequência de contaminação parasitológica encontrada em cada um dos produtores visitados, uma vez que se pretendeu avaliar de forma mais ampla as condições sanitárias das hortaliças orgânicas produzidas na Região Metropolitana de Curitiba - PR.

Todas as alfaces analisadas apresentaram algum tipo de estrutura parasitária, semelhante aos resultados encontrados por Santana et al. (2006), onde também todas as amostras de alface analisadas, independente do sistema de cultivo, apresentaram presença de parasitas. Um dos fatores que pode ter contribuído para esse elevado índice foi a alta pluviosidade no período da coleta das amostras. A chuva, ao cair no solo, faz que partículas de terra acabem se alojando entre as folhas de alface, possibilitando a permanência de estruturas parasitárias. Erdogrul e Sener (2005) encontraram maiores taxas de contaminação nas alfaces coletadas nos períodos de chuva mais frequente. Contrariamente, Oliveira e Germano (1992) verificaram que nas épocas chuvosas, os percentuais de contaminação foram sensivelmente mais baixos.

Tabela 1. Coliformes totais, coliformes fecais e Salmonella sp. em hortaliças orgânicas da região metropolitana de Curitiba - PR.

\begin{tabular}{|c|c|c|c|c|}
\hline Hortaliça/Produtor & Região Metropolitana de Curitiba-PR & Coliformes totais NMP.g $^{-1}$ & Coliformes fecais NMP.g ${ }^{-1}$ & Salmonella sp. \\
\hline Alface/Produtor 1 & São José dos Pinhais & $\geq 2,4 \times 10^{3}$ & $\geq 2,4 \times 10^{3}$ & Ausente \\
\hline Alface/Produtor 2 & São José dos Pinhais & $1,1 \times 10^{3}$ & $2,1 \times 10^{2}$ & Presente \\
\hline Alface/Produtor 3 & São José dos Pinhais & $1,5 \times 10^{2}$ & $3,9 \times 10$ & Ausente \\
\hline Alface/Produtor 4 & São José dos Pinhais & $1,1 \times 10^{3}$ & $4,3 \times 10$ & Ausente \\
\hline Alface/Produtor 5 & São José dos Pinhais & $2,4 \times 10^{2}$ & $4,3 \times 10$ & Ausente \\
\hline Tomate/Produtor 6 & São José dos Pinhais & $<3$ & $<3$ & Ausente \\
\hline Tomate/Produtor 7 & São José dos Pinhais & $<3$ & $<3$ & Ausente \\
\hline Tomate/Produtor 8 & São José dos Pinhais & 27 & $<3$ & Ausente \\
\hline Tomate/Produtor 9 & São José dos Pinhais & 9 & $<3$ & Ausente \\
\hline Cenoura/Produtor 10 & São José dos Pinhais & $1,5 \times 10^{2}$ & $3,9 \times 10$ & Ausente \\
\hline Cenoura/Produtor 11 & Colombo & $1,5 \times 10^{2}$ & $<3$ & Ausente \\
\hline Cenoura/Produtor 12 & Colombo & 27 & $<3$ & Ausente \\
\hline Cenoura/Produtor 13 & Colombo & $2,4 \times 10^{2}$ & $2,1 \times 10^{2}$ & Presente \\
\hline
\end{tabular}


As formas parasitárias de maior ocorrência nas alfaces orgânicas foram ovos de ancilostomídeo (26,7\%), ovos de ácaro (26,7\%), ácaros (26,7\%), cistos de Entamoeba sp. (20\%) e insetos (pulgões) (20\%). Mais de $60 \%$ das alfaces analisadas por Falavigna et al. (2005), provenientes do sistema convencional de produção, encontravam-se parasitadas por protozoários e helmintos, sendo a forma mais prevalente ovos de ancilostomídeo.

Segundo Gelli et al. (1979), a estrutura do vegetal interfere com o grau de contaminação que possa apresentar. Assim, hortaliças com folhas múltiplas, com grande área de contato, permitem maior fixação de formas parasitárias. Além da estrutura vegetal, alface, repolho e outras folhosas têm maiores contaminações por estarem por um tempo maior em contato com o solo e, dessa forma, continuamente expostas à contaminação (ERDOGRUL; SENER, 2005).

Conforme relatado, as diferenças nas estruturas das hortaliças analisadas e a proximidade com o solo interferiram nos resultados encontrados. A taxa de contaminação das amostras de alface foi significativamente superior às amostras de cenoura.

Cabe destacar que, nas doze amostras de tomate orgânico analisadas, não foram detectadas parasitas, assim como em algumas amostras de cenoura orgânica. $\mathrm{O}$ tomate, assim

Tabela 2. Frequência de formas parasitárias em amostras de hortaliças orgânicas da Região Metropolitana de Curitiba - PR.

\begin{tabular}{lcccccc}
\hline \multicolumn{1}{c}{ Formas parasitárias } & \multicolumn{2}{c}{$\begin{array}{c}\text { Alface } \\
\mathrm{n}=15\end{array}$} & \multicolumn{2}{c}{$\begin{array}{c}\text { Cenoura } \\
\mathrm{n}=12\end{array}$} & $\begin{array}{c}\text { Tomate } \\
\mathrm{n}=12\end{array}$ \\
\hline & $\mathrm{F}$ & $\%$ & $\mathrm{~F}$ & $\%$ & $\mathrm{~F}$ & $\%$ \\
Ovos de ancilostomídeo & 4 & 26,7 & 1 & 12,5 & - & - \\
Cistos de Entamoeba sp. & 3 & 20 & 1 & 12,5 & - & - \\
Entamoeba sp. & - & - & 2 & 25 & - & - \\
Larvas de nematóide & 1 & 6,7 & - & - & - & - \\
Ovos de nematóide & 2 & 13,3 & - & - & - & - \\
Ovos de Toxocara sp. & - & - & 1 & 12,5 & - & - \\
Insetos (pulgões) & 3 & 20 & - & - & - & - \\
Ovos de ácaro & 4 & 26,7 & - & - & - & - \\
Ácaros & 4 & 26,7 & - & - & - & - \\
\hline
\end{tabular}

$\mathrm{n}=$ número de amostras analisadas; $\mathrm{F}=$ frequência. como a cenoura, apresenta superfície lisa, o que dificultaria a permanência de estruturas parasitárias. No entanto, a cenoura é uma hortaliça que fica permanentemente em contato com o solo, por isso a contaminação por parasitas tende a ser superior.

Ovos de Toxocara sp. foram identificados em apenas uma amostra de cenoura orgânica. A ocorrência desse helminto nas hortaliças pode ser proveniente de solos contaminados com ovos do parasita originário de cães ou gatos parasitados, ou devido ao comprometimento do sistema de irrigação (MAGNAVAL et al., 1997).

A presença de cistos de Entamoeba sp. foi detectada em aproximadamente $13 \%$ das hortaliças orgânicas analisadas. Apesar de não ser considerado um organismo patogênico, esse protozoário apresenta grande valor como indicador de condições higiênicas inadequadas, uma vez que a sua presença indica contaminação por matéria fecal de origem humana (PAULA et al., 2003).

\subsection{Avaliação físico-química}

Os resultados das análises físico-químicas das amostras de alface, tomate e cenoura estão apresentados nas Tabela 3, 4 e 5 , respectivamente.

$\mathrm{Na}$ revisão de Bourn e Prescott (2002), os alimentos orgânicos apresentam normalmente um teor menor de umidade do que os convencionais, sendo que os resultados apresentados nas Tabelas 3, 4 e 5 corroboram os dados apresentados por aqueles autores e também os disponíveis na TACO (UNICAMP, 2006) para as espécies aqui analisadas.

Diversos autores relatam que os alimentos produzidos sob sistema orgânico possuem, frequentemente, teores de vitamina C superiores aos produzidos convencionalmente (CLARKE; MERROW, 1979; MULLER; HIPPE, 1987; LECLERK et al., 1991; BOURN; PRESCOTT, 2002; WILLIAMS, 2002; MAGKOS; ARVANITI; ZAMPELAS, 2003). Neste trabalho, foi possível observar que os teores de vitamina $\mathrm{C}$ das amostras de alface, tomate e cenoura orgânicas analisadas estavam acima dos valores registrados na TACO (UNICAMP, 2006), corroborando as literaturas citadas.

Tabela 3. Características físico-químicas de alfaces obtidas pelo sistema de cultivo orgânico da região metropolitana de Curitiba - PR.

\begin{tabular}{|c|c|c|c|c|c|c|}
\hline Constituintes & TACO (2006) & Produtor 1 & Produtor 2 & Produtor 3 & Produtor 4 & Produtor 5 \\
\hline Umidade $(\mathrm{g})$ & 97,2 & $93,07 \pm 1,09^{\mathrm{ns}}$ & $92,41 \pm 1,18^{\mathrm{ns}}$ & $93,02 \pm 1,18^{\mathrm{ns}}$ & $92,29 \pm 0,78^{\mathrm{ns}}$ & $92,59 \pm 0,95^{\mathrm{ns}}$ \\
\hline Matéria seca (g) & nd & $6,93 \pm 1,09^{\mathrm{ns}}$ & $7,59 \pm 0,69^{\text {ns }}$ & $6,98 \pm 1,18^{\mathrm{ns}}$ & $7,71 \pm 0,78^{\mathrm{ns}}$ & $7,41 \pm 0,95^{\mathrm{ns}}$ \\
\hline Cinzas (g) & 0,3 & $0,96 \pm 0,02^{\mathrm{a}}$ & $0,98 \pm 0,002^{c}$ & $0,98 \pm 0,004^{\mathrm{e}}$ & $0,93 \pm 0,004^{\mathrm{b}}$ & $0,95 \pm 0,009^{\mathrm{b}}$ \\
\hline Proteína (g) & 0,6 & $0,89 \pm 0,04^{\mathrm{ns}}$ & $0,90 \pm 0,04^{\mathrm{ns}}$ & $0,90 \pm 0,03^{\mathrm{ns}}$ & $0,90 \pm 0,03^{\mathrm{ns}}$ & $0,93 \pm 0,03^{\text {ns }}$ \\
\hline Lipídios (g) & 0,1 & $0,21 \pm 0,03^{\mathrm{ns}}$ & $0,24 \pm 0,03^{\mathrm{a}}$ & $0,22 \pm 0,04^{\mathrm{ns}}$ & $0,20 \pm 0,03^{\mathrm{ns}}$ & $0,18 \pm 0,01^{\mathrm{b}}$ \\
\hline Carboidratos (g) & 1,7 & $4,87 \pm 1,08^{\mathrm{ns}}$ & $5,47 \pm 0,71^{\mathrm{ns}}$ & $4,88 \pm 1,18^{\mathrm{ns}}$ & $5,68 \pm 0,76^{\mathrm{ns}}$ & $5,35 \pm 0,94^{\mathrm{ns}}$ \\
\hline Fibra alimentar (g) & 1,0 & $1,93 \pm 0,05^{a}$ & $2,04 \pm 0,05^{\mathrm{ns}}$ & $2,28 \pm 0,23^{\mathrm{b}}$ & $2,02 \pm 0,12^{\mathrm{ns}}$ & $2,04 \pm 0,09^{\text {ns }}$ \\
\hline $\mathrm{pH}$ & nd & $6,11 \pm 0,06^{\mathrm{a}}$ & $6,11 \pm 0,03^{e}$ & $6,19 \pm 0,03^{b}$ & $6,04 \pm 0,03^{c}$ & $6,22 \pm 0,04^{\mathrm{b}}$ \\
\hline Vitamina C (mg) & 11 & $20,31 \pm 3,20^{\mathrm{ns}}$ & $21,02 \pm 2,61^{\mathrm{ns}}$ & $21,05 \pm 3,03^{\mathrm{ns}}$ & $21,01 \pm 1,41^{\mathrm{ns}}$ & $21,33 \pm 1,75^{\mathrm{ns}}$ \\
\hline Valor calórico (kcal) & 9 & 17,21 & 19,48 & 15,98 & 20,04 & 18,58 \\
\hline
\end{tabular}

ns = não significativo; $n d$ = não disponível. Valores por $100 \mathrm{~g}$ de amostra. Médias na mesma linha com letras iguais não diferem estatisticamente ( $\mathrm{p} \leq 0,05$ ); Médias de três repetições \pm DP. 
Tabela 4. Características físico-químicas de tomates obtidos pelo sistema de cultivo orgânico da região metropolitana de Curitiba-PR.

\begin{tabular}{lccccc}
\hline \multicolumn{1}{c}{ Constituintes } & TACO (2006) & Produtor 6 & Produtor 7 & Produtor 8 & Produtor 9 \\
\hline Umidade (g) & 95,1 & $93,37 \pm 0,72^{\text {ns }}$ & $92,90 \pm 0,27^{\text {ns }}$ & $92,46 \pm 1,45^{\text {ns }}$ & $92,59 \pm 0,41^{\text {ns }}$ \\
Matéria seca (g) & nd & $6,63 \pm 0,72^{\text {ns }}$ & $7,10 \pm 0,27^{\text {ns }}$ & $7,54 \pm 1,45^{\text {ns }}$ & $7,41 \pm 0,41^{\text {ns }}$ \\
Cinzas (g) & 0,5 & $0,43 \pm 0,01^{\mathrm{a}}$ & $0,48 \pm 0,03^{\mathrm{b}}$ & $0,43 \pm 0,05^{\mathrm{a}}$ & $0,45 \pm 0,03^{\mathrm{a}}$ \\
Proteína (g) & 1,1 & $0,93 \pm 0,05^{\mathrm{ns}}$ & $0,90 \pm 0,03^{\mathrm{ns}}$ & $0,90 \pm 0,03^{\mathrm{ns}}$ & $0,90 \pm 0,02^{\mathrm{ns}}$ \\
Lipídios (g) & 0,2 & $0,17 \pm 0,03^{\mathrm{ns}}$ & $0,14 \pm 0,02^{\mathrm{ns}}$ & $0,16 \pm 0,02^{\mathrm{ns}}$ & $0,16 \pm 0,03^{\mathrm{ns}}$ \\
Carboidratos (g) & 3,1 & $5,10 \pm 0,7^{\mathrm{ns}}$ & $5,58 \pm 0,21^{\mathrm{ns}}$ & $6,05 \pm 1,43^{\mathrm{ns}}$ & $5,90 \pm 0,39^{\mathrm{ns}}$ \\
Fibra alimentar (g) & 1,2 & $1,17 \pm 0,04^{\mathrm{ab}}$ & $1,09 \pm 0,06^{\mathrm{a}}$ & $1,23 \pm 0,07^{\mathrm{b}}$ & $1,16 \pm 0,04^{\mathrm{ab}}$ \\
pH & $\mathrm{nd}$ & $4,54 \pm 0,1^{\mathrm{a}}$ & $4,42 \pm 0,15^{\mathrm{a}}$ & $4,71 \pm 0,07^{\mathrm{b}}$ & $4,74 \pm 0,07^{\mathrm{b}}$ \\
Vitamina C (mg) & 21,2 & $31,10 \pm 0,81^{\mathrm{ns}}$ & $32,91 \pm 1,48^{\mathrm{a}}$ & $30,82 \pm 0,89^{\mathrm{b}}$ & $32,43 \pm 1,59^{\mathrm{ns}}$ \\
Valor calórico (kcal) & 15 & 20,97 & 22,82 & 24,32 & 24,00 \\
\hline
\end{tabular}

ns = não significativo; nd = não disponível. Valores por $100 \mathrm{~g}$ de amostra. Médias na mesma linha com letras iguais não diferem estatisticamente (p $\leq$ 0,05); Médias de três repetições \pm DP.

Tabela 5. Características físico-químicas de cenouras obtidas pelo sistema de cultivo orgânico da região metropolitana de Curitiba-PR.

\begin{tabular}{|c|c|c|c|c|c|}
\hline Constituintes & TACO (2006) & Produtor 10 & Produtor 11 & Produtor 12 & Produtor 13 \\
\hline Umidade (g) & 90,1 & $87,74 \pm 1,43^{\mathrm{ns}}$ & $88,59 \pm 1,94^{\mathrm{ns}}$ & $88,15 \pm 2,02^{\mathrm{ns}}$ & $87,54 \pm 1,23^{\mathrm{ns}}$ \\
\hline Matéria seca (g) & nd & $12,26 \pm 1,44^{\mathrm{ns}}$ & $11,41 \pm 1,94^{\mathrm{ns}}$ & $11,83 \pm 2,02^{\mathrm{ns}}$ & $12,46 \pm 1,23^{\mathrm{ns}}$ \\
\hline Cinzas (g) & 0,9 & $1,11 \pm 0,05^{\mathrm{ns}}$ & $1,12 \pm 0,05^{\mathrm{ns}}$ & $1,07 \pm 0,04^{\mathrm{ns}}$ & $1,11 \pm 0,04^{\mathrm{ns}}$ \\
\hline Proteína (g) & 1,3 & $1,40 \pm 0,06^{\mathrm{ns}}$ & $1,40 \pm 0,02^{\mathrm{ns}}$ & $1,43 \pm 0,05^{\mathrm{ns}}$ & $1,46 \pm 0,06^{\mathrm{ns}}$ \\
\hline Lipídios (g) & 0,2 & $0,26 \pm 0,03^{\mathrm{ns}}$ & $0,26 \pm 0,02^{\mathrm{ns}}$ & $0,30 \pm 0,02^{\mathrm{ns}}$ & $0,29 \pm 0,02^{\mathrm{ns}}$ \\
\hline Carboidratos (g) & 7,7 & $9,49 \pm 0,57^{\mathrm{ns}}$ & $8,63 \pm 1,50^{\mathrm{ns}}$ & $9,05 \pm 0,96^{\mathrm{ns}}$ & $9,60 \pm 0,51^{\text {ns }}$ \\
\hline Fibra alimentar (g) & 3,2 & $3,58 \pm 0,38^{\mathrm{ns}}$ & $3,57 \pm 0,48^{\mathrm{ns}}$ & $3,87 \pm 0,24^{\mathrm{ns}}$ & $3,93 \pm 0,24^{\mathrm{ns}}$ \\
\hline $\mathrm{pH}$ & nd & $6,29 \pm 0,14^{\mathrm{a}}$ & $5,98 \pm 0,08^{b}$ & $5,82 \pm 0,17^{\mathrm{b}}$ & $6,27 \pm 0,12^{\mathrm{a}}$ \\
\hline Vitamina C (mg) & 5,1 & $6,13 \pm 0,21^{\mathrm{a}}$ & $6,91 \pm 0,21^{\mathrm{b}}$ & $5,93 \pm 0,65^{\mathrm{a}}$ & $6,01 \pm 0,24^{\mathrm{a}}$ \\
\hline Valor calórico (kcal) & 34 & 31,58 & 28,18 & 29,14 & 31,13 \\
\hline
\end{tabular}

ns = não significativo; nd = não disponível. Valores por $100 \mathrm{~g}$ de amostra. Médias na mesma linha com letras iguais não diferem estatisticamente (p $\leq$ 0,05); Médias de três repetições $\pm \mathrm{DP}$.

Como o teor de umidade nas hortaliças orgânicas analisadas foi sensivelmente inferior ao disponibilizado (UNICAMP, 2006), houve um acréscimo no valor calórico nas amostras de alface e tomate analisadas. No entanto, faz-se importante destacar que a determinação do valor nutricional das hortaliças orgânicas coletadas na RMC foi realizada com o intuito de disponibilizar maiores dados referente à composição química de alimentos produzidos sob sistema de cultivo orgânico e não indicar a superioridade de alimentos orgânicos frente àqueles produzidos de forma convencional, pois, para se fazer esse tipo de inferência, inúmeros fatores devem ser devidamente controlados.

Segundo Smith (1993), a composição química de alimentos de origem vegetal apresenta diferenças em função de fatores associados ao cultivo e ao ambiente, como local de plantio, adubação, ocorrência de pragas, diferenças edafoclimáticas, período de colheita, idade e características genéticas da planta, entre outros.

\section{Conclusões}

Ainda que alguns trabalhos afirmem a superioridade nutricional de alimentos produzidos organicamente, o objetivo deste estudo foi apresentar mais dados sobre a composição físico-química de hortaliças produzidas no sistema orgânico. As amostras de alface e tomate oriundas de cultivo orgânico analisadas neste trabalho apresentaram um maior valor energético, menor teor de umidade e maior teor de vitamina $C$ em relação aos dados disponibilizados pela Tabela Brasileira de Composição de Alimentos.

A qualidade sanitária das amostras de alface e cenoura orgânicas foi inferior às amostras de tomate analisadas, uma vez que as primeiras apresentaram contagens de coliforme de origem fecal e Salmonella sp. superiores ao permitido pela legislação brasileira, bem como foi detectado presença de estruturas parasitárias. A contaminação dessas hortaliças pode ter ocorrido através do uso de água de irrigação contaminada, presença de animais silvestres ou domésticos, solo contaminado ou emprego de adubos orgânicos sem tempo de compostagem adequado.

Embora haja uma escassez de estudos avaliando a qualidade sanitária de alimentos produzidos no sistema orgânico, o foco deste trabalho foi o de ressaltar a importância da adoção de procedimentos que assegurem a qualidade sanitária e nutricional das hortaliças produzidas nos diferentes sistemas de cultivo empregados.

\section{Referências bibliográficas}

AMERICAN PUBLIC HEALTH ASSOCIATION - APHA. Technical committee on microbiological methods for food. In: VANDERZANT, C.; SPLITTSTOESSER, D. F. Compendium of methods for the microbiological examination of foods. $3 \mathrm{ed}$. Washington, 1992. p. 336-383.

ASSOCIAÇÃO BRASILEIRA DE NORMAS TÉCNICAS - ABNT. MB n. 3463. Bactérias coliformes totais, coliformes fecais e Escherichia 
coli em alimentos - determinação do número mais provável. Rio de Janeiro, 1991.

ASSOCIATION OF OFFICIAL ANALYTICAL CHEMISTS - AOAC. Official methods of analysis of the AOAC. 17 ed. Washington, 2002.

BALIONI, G. A. et al. Avaliação higiênico-sanitária de alfaces agroecológicas e cultivadas com agrotóxicos, comercializadas na região de Campinas, SP. Higiene Alimentar, v. 17, n. 2, p. 73-77, 2003.

BOURN, D.; PRESCOTT, J. A comparison of the nutritional value, sensory qualities, and food safety of organically and conventionally produced food. Critical Reviews in Food Science and Nutrition, v. 42, n. 1, p. 1-34, 2002.

BRASIL. Agência Nacional de Vigilância Sanitária - ANVISA. RDC n. 12, de 02 de janeiro de 2001. Regulamento técnico sobre padrões microbiológicos em alimentos. Diario Oficial da União, Poder Executivo, Brasília, DF, 10 jan. 2001. Disponível em: <http:// www.anvisa.gov.br/legis/resol/12_01rdc.htm>. Acesso em: 10 jun. 2006.

CHINNICI, G.; DÁMICO, M.; PECORINO, B. A multivariate statistical analysis on the consumers of organic products. British Food Journal, v. 104, n. 3, p. 187-199, 2002.

CLARKE, R. P.; MERROW, S. B. Nutrient composition of tomatoes homegrown under different cultural procedures. Ecology Food Nutrition, v. 8, n. 1, p. 37-46, 1979.

ERDOGRUL, O.; SENER, H. The contamination of various fruit and vegetable with Enterobius vermicularis, Ascaris eggs, Entamoeba histolyca cysts and Giardia cysts. Food Control, v. 16, n. 6, p. 557-560, 2005.

FALAVIGNA, L. M. et al. Qualidade de hortaliças comercializadas no noroeste do Paraná. Brasil. Parasitologia Latinoamericana, v. 60, n. 3/4, p. 144-149, 2005.

FREWER, L.; SHEPHERD, D.; SPARKS, P. The interrelationship between perceived knowledge, control and risk associated with a range of food-related hazards targeted at the individual, other people and society. Journal Food Safety, v. 4, n. 8, p. 19-40, 1994.

GELLI, D. S. et al. Condições higiênico-sanitárias de hortaliças comercializadas na cidade de São Paulo, SP, Brasil. Revista do Instituto Adolfo Lutz, v. 39, n. 1, p. 37-43, 1979.

INSTITUTO ADOLFO LUTZ - IAL. Métodos físico-químicos para análise de alimentos. 4 ed. Brasília: Anvisa, 2005.

MAGKOS, F.; ARVANITI, F.; ZAMPELAS, A. Organic food: nutritious food or food for thought? A review of the evidence. International Journal Food Science and Nutrition, v. 54, n. 5, p. 357-71, 2003.
MAGNAVAL, J. F. et al. Human Toxocara infection of the central nervous system and neurological disorders: a case-control study. Parasitology, v. 115, n. 5, p. 537-543, 1997.

MULLER, K.; HIPPE, J. Influence of differences in nutrition on important quality characteristics of some agricultural crops. Plant and Soil, v. 100, n. 1-3, p. 35-45, 1987.

OBUOBIE, E. et al. Irrigated urban vegetable production in Ghana: characteristics, benefits and risks. Ghana: International Water Management Institute, 2006. p. 90-102.

OLIVEIRA, C. A. F.; GERMANO, M. L. Estudo da ocorrência de enteroparasitas em hortaliças comercializadas na região metropolitana de São Paulo, Brasil: pesquisa de helmintos. Revista de Saúde Pública, v. 26, n. 4, p. 283-289, 1992.

OLIVEIRA, M. L. S. et al. Análise microbiológica de alface (Lactuca sativa, L.) e tomate (Solanum lycopersicum, L.), comercializadas em feira-livres da cidade de Belém, Pará. Higiene Alimentar, v. 20, n. 143, p. 96-101, 2006.

PAULA, P. et al. Contaminação microbiológica e parasitológica em alfaces (Lactuca sativa) de restaurantes self-service de Niterói, RJ. Revista da Sociedade Brasileira de Medicina Tropical, v. 36, n. 4, p. 535-537, 2003.

SABA, A.; ROSATI, S.; VASSALLO, M. Biotechnology in agriculture: perceived risks, benefits and attitudes in Italy. British Food Journal, v. 102, n. 2, p. 114-121, 2000.

SANTANA, L. R. et al. Qualidade física, microbiológica e parasitológica de alfaces (Lactuca sativa) de diferentes sistema de cultivo. Ciência Tecnologia de Alimentos, v. 26, n. 2, p. 264-269, 2006.

SMITH, B. L. Organic foods vs. supermarket foods: element levels. Journal of Applied Nutrition, v. 45, n. 1, p. 35-39, 1993.

STEPHENSON, J. Public health experts take aim at a moving target: food borne infections. Journal of the American Medical Association, v. 277, n. 2, p. 97-98, 1997.

TAKAYANAGUI, O. M. et al. Fiscalização de verduras comercializadas no município de Ribeirão Preto, SP. Revista da Sociedade Brasileira de Medicina Tropical, v. 34, n. 1, p. 37-41, 2001.

UNIVERSIDADE ESTADUAL DE CAMPINAS - UNICAMP. Tabela Brasileira de Composição de Alimentos: TACO. Versão 2. Campinas, 2006. Disponível em: <http.www.unicamp.br/nepa/ taco>. Acesso em: 20 dez. 2006.

UNIVERSIDADE DE SÃO PAULO - USP. Tabela brasileira de composição dos alimentos. Campinas, 2007. Disponível em:<http:www.fcf.usp.br/>. Acesso em: 12 de mar. 2007.

WILLIAMS, C. M. Nutritional quality of organic food: shades of grey or shades of green? Proceedings of the Nutrition Society, v. 61, n. 1, p. 19-24, 2002. 